\title{
A robust mechanism for strengthening of the Brewer-Dobson circulation in response to climate change: critical-layer control of subtropical wave breaking
}

Article

Published Version

Shepherd, T. G. and McLandress, C. (2011) A robust mechanism for strengthening of the Brewer-Dobson circulation in response to climate change: critical-layer control of subtropical wave breaking. Journal of the Atmospheric Sciences, 68 (4). pp. 784-797. ISSN 1520-0469 doi: https://doi.org/10.1175/2010JAS3608.1 Available at https://centaur.reading.ac.uk/31555/

It is advisable to refer to the publisher's version if you intend to cite from the work. See Guidance on citing.

To link to this article DOI: http://dx.doi.org/10.1175/2010JAS3608.1

Publisher: American Meteorological Society

All outputs in CentAUR are protected by Intellectual Property Rights law, including copyright law. Copyright and IPR is retained by the creators or other copyright holders. Terms and conditions for use of this material are defined in the End User Agreement. 


\section{www.reading.ac.uk/centaur}

\section{CentAUR}

Central Archive at the University of Reading

Reading's research outputs online 


\title{
A Robust Mechanism for Strengthening of the Brewer-Dobson Circulation in Response to Climate Change: Critical-Layer Control of Subtropical Wave Breaking
}

\author{
TheOdORE G. SHEPHERD AND CHARLES MCLANDRESS \\ Department of Physics, University of Toronto, Toronto, Ontario, Canada
}

(Manuscript received 28 July 2010, in final form 19 October 2010)

\begin{abstract}
Climate models consistently predict a strengthened Brewer-Dobson circulation in response to greenhouse gas (GHG)-induced climate change. Although the predicted circulation changes are clearly the result of changes in stratospheric wave drag, the mechanism behind the wave-drag changes remains unclear. Here, simulations from a chemistry-climate model are analyzed to show that the changes in resolved wave drag are largely explainable in terms of a simple and robust dynamical mechanism, namely changes in the location of critical layers within the subtropical lower stratosphere, which are known from observations to control the spatial distribution of Rossby wave breaking. In particular, the strengthening of the upper flanks of the subtropical jets that is robustly expected from GHG-induced tropospheric warming pushes the critical layers (and the associated regions of wave drag) upward, allowing more wave activity to penetrate into the subtropical lower stratosphere. Because the subtropics represent the critical region for wave driving of the Brewer-Dobson circulation, the circulation is thereby strengthened. Transient planetary-scale waves and synoptic-scale waves generated by baroclinic instability are both found to play a crucial role in this process. Changes in stationary planetary wave drag are not so important because they largely occur away from subtropical latitudes.
\end{abstract}

\section{Introduction}

The mass circulation of the stratosphere, known as the Brewer-Dobson circulation (BDC), is characterized by upwelling in the tropics and downwelling in the extratropics (Andrews et al. 1987; Plumb 2002; Shepherd 2007). This overturning circulation controls the mass exchange between the stratosphere and troposphere (Holton 1990) and is driven by torques, known as "wave drag," exerted by waves propagating up from the troposphere (Holton et al. 1995; Plumb and Eluszkiewicz 1999; Semeniuk and Shepherd 2001). The BDC plays a critical role in chemistry-climate coupling because it exerts a strong control on the lifetimes of chlorofluorocarbons (CFCs) and other greenhouse gases (GHGs), the entry value of stratospheric water vapor, tropopause temperature and height, the flux of stratospheric ozone into the troposphere, and both interannual and long-term changes in lower-stratospheric ozone.

Corresponding author address: Theodore G. Shepherd, Department of Physics, University of Toronto, 60 St. George St., Toronto ON M5S 1A7, Canada.

E-mail: tgs@atmosp.physics.utoronto.ca
Stratosphere-resolving climate models consistently predict a strengthening of the $\mathrm{BDC}$ in response to $(\mathrm{GHG}$ induced) climate change (Butchart et al. 2006, 2010). Because the BDC is wave driven, such a change necessarily involves changes in stratospheric wave drag. Furthermore, the relevant wave-drag changes must necessarily occur in subtropical latitudes, because these represent the "turnaround latitudes" between tropical upwelling and extratropical downwelling and hence control the stratospheric overturning circulation (Plumb and Eluszkiewicz 1999; Semeniuk and Shepherd 2001; Butchart et al. 2006). Wave-drag changes located in the vicinity of these latitudes will drive vertical motion of one sign on the equatorward side and of the opposite sign on the poleward side, which will strengthen or weaken the BDC. Changes in wave drag poleward of the turnaround latitudes (or within the deep tropics) can only lead to a latitudinal redistribution of the downwelling (or upwelling) within their respective regions. Although they are of importance for other reasons, such changes cannot directly affect the BDC.

Changes in stratospheric wave driving of the BDC can in principle arise in three distinct ways. They can arise from changes in the strength of the wave generation within the troposphere, from changes in the latitudinal 
distribution of wave forcing within the stratosphere (provided these occur in the vicinity of the turnaround latitudes), and from changes in the extent of penetration of the tropospheric wave forcing into the stratosphere. In the case of climate change, relevant factors for the latter include the weakened static stability around the tropopause and the strengthened upper flank of the subtropical jets, both of which are robust outcomes of tropospheric warming and stratospheric cooling. The strengthened upper flank of the subtropical jets arises mainly from the tropospheric warming, because the $\mathrm{CO}_{2}$-induced stratospheric cooling is largely independent of latitude (Fomichev et al. 2007). In contrast, the tropospheric warming is confined to below the tropopause, which slopes downward with increasing latitude, resulting in a more equatorward latitudinal temperature gradient that strengthens the upper flank of the subtropical jets.

Arguably the first significant paper on the strengthened BDC was that of Rind et al. (1990). Using 3-yr simulations from a middle atmosphere version of the Goddard Institute for Space Studies (GISS) general circulation model (GCM) forced by sea surface temperatures and sea ice distributions (jointly referred to as SSTs) projected by the parent coupled atmosphere-ocean model, Rind et al. (1990) found that a doubled $\mathrm{CO}_{2}$ climate led to a strengthening of the stratospheric residual circulation, which resulted in about a $20 \%-25 \%$ increase in the net tropical upwelling (defined by the extrema in the mass streamfunction) in the lower stratosphere $(46 \mathrm{hPa})$ during Northern Hemisphere $(\mathrm{NH})$ winter. They showed that these circulation changes arose mainly from the tropospheric GHG forcing, as reflected in the SST changes, and using what appears to be an early version of "downward control" (Haynes et al. 1991), they argued that both resolved waves and parameterized gravity waves contributed significantly to the strengthening of the circulation.

Rind et al. (1990) clearly recognized the potential significance of their finding. They suggested that a strengthened BDC would lead to a faster removal of $\mathrm{N}_{2} \mathrm{O}$ and CFCs from the atmosphere and to a redistribution of ozone in the lower stratosphere from the tropics to the midlatitudes, reducing column ozone in the tropics and increasing it in midlatitudes. The predictions for column ozone were confirmed by Mahfouf et al. (1994) using a stratosphere-resolving chemistry-climate model (CCM) and more recently by Shepherd (2008), who found that in $\mathrm{NH}$ midlatitudes the circulation changes lead to an ozone superrecovery in the second half of the twenty-first century in excess of the magnitude of CFC-induced ozone depletion. Rind et al. (1990) also suggested that the ozone redistribution would affect the penetration of UV radiation into the troposphere, which was confirmed by Hegglin and Shepherd (2009).
During the last $20 \mathrm{yr}$, the GCM results of Rind et al. (1990) have been confirmed in all essential respects by many subsequent studies using a variety of climate models (most recently with interactive chemistry) with much higher spatial resolution, much longer integrations, and transient as well as time-slice simulations. Using two 60-yr transient simulations with the troposphere-stratosphere version of the Met Office Unified Model, Butchart and Scaife (2001) found about a $3 \%$ decade $^{-1}$ increase in the net upward mass flux at $70 \mathrm{hPa}$ in response to increasing GHG concentrations. Butchart and Scaife (2001) applied the "downward control" principle (Haynes et al. 1991) in a quantitative manner to show that the strengthened tropical upwelling arose from strengthened wave drag in the subtropical lower stratosphere, around $30^{\circ}$ latitude, which in their model was mainly due to resolved waves, and argued that it resulted from increased wave penetration into the subtropical lower stratosphere as a consequence of the strengthened zonal winds in this region.

The first model-intercomparison study of Butchart et al. (2006) established that the strengthened BDC is ubiquitous in climate models, whereas Butchart et al. (2010) showed a convergence in CCMs forced by the same transient GHG scenario toward a circulation trend (at $70 \mathrm{hPa}$ ) of about $2 \%$ decade $^{-1}$, which is quite consistent with Rind et al. (1990). Rind et al. (2002), Sigmond et al. (2004), Fomichev et al. (2007), Olsen et al. (2007), and Oman et al. (2009) confirmed that the circulation changes are primarily driven by tropospheric warming rather than by radiative effects within the stratosphere itself.

Butchart et al. $(2006,2010)$ confirmed that the strengthened BDC arises from increased stratospheric drag from both resolved and parameterized waves; on average, the resolved waves contribute roughly two-thirds of the total, although the split between the two is highly model dependent. Li et al. (2008) and McLandress and Shepherd (2009; hereafter MS09) confirmed Rind et al.'s (1990) speculation that the strengthened upper flank of the subtropical jets increases the orographic gravity wave drag (GWD) in the lower stratosphere by raising the breaking altitudes of the orographic gravity waves, thereby allowing more gravity wave momentum flux to penetrate into the stratosphere. Although the magnitude of the enhancement can be expected to depend on the details of the parameterization, the importance of orographic GWD for BDC changes should not be surprising given that the Himalayas lie at subtropical latitudes.

Absent is any consensus on the mechanism behind the increase in stratospheric drag from the resolved waves, which presumably consist of Rossby waves. Rind et al. (1990) assumed the increase was due to planetary waves 
and speculated that it arose from a combination of a decrease in static stability (increasing the energy of the planetary waves) and improved propagation conditions from the zonal-mean zonal-wind changes. The appeal to "improved propagation conditions" from the strengthened upper flank of the subtropical jets has been subsequently invoked by several authors (e.g., Butchart and Scaife 2001; Garcia and Randel 2008), but this rather vague statement does not identify the physical mechanism. Rind et al. (1998) refined the argument by suggesting that the main mechanism was a change in refractive index associated with the strengthened upper flank of the subtropical jets. This argument has subsequently been invoked by several authors (e.g., Olsen et al. 2007; Oman et al. 2009; Calvo and Garcia 2009), but it faces several difficulties as an explanation of the changes. First, the concept of refractive index relies on the vertical and meridional wavelengths of the planetary waves being much smaller than the characteristic vertical and meridional scales of the background flow, but if anything the converse is true in the vicinity of the subtropical jet. Second, it is not possible to convert changes in refractive index into a testable prediction of wave-drag changes without the use of a linear planetary-wave model, and this has not yet been done. In addition, several studies (Butchart and Scaife 2001; MS09) have found a strengthened BDC without any discernible change in refractive index.

Another possibility is that planetary-wave forcing within the troposphere increases in response to GHGinduced tropospheric warming. Deckert and Dameris (2008) argued that this was the case in tropical latitudes because of increased convective activity, which leads to increased forcing of equatorially trapped quasi-stationary Rossby waves. However, Deckert and Dameris (2008) also showed (see their Fig. 3) that the strengthened tropical upwelling resulting from this process, which maximizes in boreal summer, only leads to recirculation within the tropical stratosphere. Although this circulation feature is certainly relevant to lower-stratospheric temperature, water vapor, and ozone within the tropics, as noted earlier it is not relevant to the net tropical upwelling and thus not to the BDC as usually understood (whose response to climate change is in any case found to maximize in boreal winter).

Calvo and Garcia (2009) invoked the Deckert and Dameris (2008) mechanism to explain future tropical upwelling changes in Whole Atmosphere Community Climate Model (WACCM) simulations over the $22^{\circ} \mathrm{S}-$ $22^{\circ} \mathrm{N}$ latitude band, but they did not quantify the contribution to the net tropical upwelling, which occurs over a considerably wider latitudinal band. Moreover, to explain the past changes in their model, they appealed instead to increased penetration into the stratosphere of resolved wave fluxes from midlatitudes, and it is not clear why the explanations should be different in the two time periods if they are both due to climate change.

No study so far has identified a strengthened forcing of waves within the extratropical troposphere that could drive a strengthened BDC. Indeed, Butchart and Scaife (2001), Sigmond et al. (2004), and Garcia and Randel (2008) all found no discernible increase in resolved wave forcing from the extratropical lower troposphere. Using a highly idealized (dry, aquaplanet) GCM, Eichelberger and Hartmann (2005) argued that increased tropospheric baroclinicity would increase the generation of transient planetary waves from enhanced baroclinic instability (via the nonlinear mechanism of Scinocca and Haynes 1998) and thereby strengthen the BDC. Although their model produced a stratospheric circulation response approximately one-quarter of the magnitude found by Butchart et al. (2010), Eichelberger and Hartmann (2005) imposed a rather extreme meridional temperature gradient at subtropical latitudes throughout most of the troposphere, so they likely obtained an exaggerated response. Also, this prediction would appear to be in contradiction with the previously quoted studies using GCMs, which found no apparent increase in wave forcing from the extratropical troposphere.

The first study to decompose the resolved stratospheric wave forcing into different zonal wavenumbers was MS09, who found that in the Canadian Middle Atmosphere Model (CMAM) the direct forcing from synoptic-scale waves contributed fully one-half of the increase in resolved stratospheric wave forcing of the BDC. Hitherto, it appears to have been the general assumption in the literature that the resolved wave drag in the subtropical lower stratosphere in the models came mainly from planetary-scale waves, without this ever having been confirmed. However, most of the mass outflow from the tropical stratosphere occurs in the lowest few kilometers of the stratosphere (Plumb 2002; Shepherd 2007; Randel et al. 2008), and the role of this outflow in "flushing" the lowermost stratosphere is evident in observed tracer distributions (Hegglin and Shepherd 2007). Synoptic-scale waves can certainly penetrate to these altitudes, as seen in satellite measurements of chemical tracers (Fig. 5 of Shepherd 2000), and have been shown to be a major driver of the observed mass flux in the subtropical lower stratosphere (Randel et al. 2008).

Therefore, although it appears that both planetaryscale and synoptic-scale Rossby waves contribute (together with parameterized orographic GWD) to the predicted strengthening of the $\mathrm{BDC}$, a robust mechanism to explain the change in resolved wave drag has yet to be advanced. However, the robustness of the model 
predictions suggests that such a mechanism ought to exist. The available evidence suggests that the mechanism is likely to involve the response of lower-stratospheric wave drag in subtropical latitudes to changes in lowerstratospheric winds arising from tropospheric warming - in particular to the strengthened upper flank of the subtropical jets-rather than to changes in wave generation within the troposphere.

Here, we propose a simple and robust dynamical mechanism for the strengthening of the BDC, based on the wellestablished observed link between Rossby wave breaking and critical layers (Randel and Held 1991). Critical layers occur where the (zonal) phase velocity of a wave matches the background (zonal) wind velocity and can generically be expected to lead to wave breaking and thus to wave drag (McIntyre and Palmer 1983; Feldstein and Held 1989; Haynes 2003). Rossby waves are generated in the troposphere with a broad range of phase velocities, and their breaking regions have been shown to follow critical layers (Randel and Held 1991). A particularly important region of Rossby wave breaking is the upper flank of the subtropical jet (Randel and Held 1991), the stratospheric part of which is optimally located for driving the BDC (Plumb 2002). Thus, with all else being equal, a strengthened upper flank of the subtropical jet should cause the critical layers on the equatorward side of the jet to move upward, and with them the Rossby wave drag, thereby leading to increased penetration of Rossby waves into, and drag within, the subtropical lower stratosphere. The purpose of this paper is to propose and test such a mechanism.

\section{Model description and diagnostics}

The simulations analyzed here are performed with the CMAM, which is the upward extension of the Canadian Centre for Climate Modelling and Analysis third-generation atmospheric GCM (CCCma-AGCM3; Scinocca et al. 2008). The CMAM includes comprehensive interactive stratospheric chemistry and radiation schemes, as well as representations of the relevant subgrid-scale processes (de Grandpré et al. 2000; Scinocca et al. 2008). The model's linear Gaussian transform grid has $32 \times 64$ points in the horizontal, corresponding to a spatial resolution of around $6^{\circ} \times 6^{\circ}$, and 71 vertical levels reaching from the ground up to around $100-\mathrm{km}$ altitude. The vertical resolution in the tropopause region is around $900 \mathrm{~m}$, coarsening to around $2 \mathrm{~km}$ in the upper stratosphere. For the calculations presented in this study, we use an ensemble of three 150-yr transient simulations starting in 1950, carried out as part of phase one of the Stratospheric Processes and their Role in Climate (SPARC) CCM Validation Activity (CCMVal-1) model intercomparison (Eyring et al. 2007). These simulations represent the combined effects of climate change and ozone depletion and recovery according to specified scenarios for GHGs and ozone-depleting substances. No further external forcing (e.g., from solar variability or volcanoes) is prescribed. The three ensemble members are forced by independent realizations of SSTs from the coupled version of the CCCma-AGCM3 under the same GHG scenario. The climate sensitivity of the latter [CCCma Coupled General Circulation Model, version 3.1 (CGCM3.1)] is $3.4^{\circ} \mathrm{C}$ (Randall et al. 2007), which corresponds roughly to the average climate sensitivity of $3.2^{\circ} \mathrm{C}$ found among models used in the Intergovernmental Panel on Climate Change (IPCC) Fourth Assessment Report (AR4).

The CMAM projections of ozone depletion/recovery and climate change are representative of the average behavior of the SPARC CCMVal-1 models (Eyring et al. 2007; Butchart et al. 2010). Furthermore, the good agreement between CMAM and observations (Eyring et al. 2006; Waugh and Eyring 2008; Shepherd 2008; MS09) gives credence to the future changes. Because here we are interested only in the effects of climate change, we examine the differences between the periods 1960-79 ("past") and 2080-99 ("future"), during both of which ozone depletion is minimal (Shepherd 2008).

Note that the first $10 \mathrm{yr}$ of the simulations (1950-59) are considered as spinup for the tracers. Therefore, they are excluded from the analysis.

The model fields are archived on pressure levels; approximate altitudes are provided on some figures using $\log$-pressure height $z$ computed from pressure $p$ using $z=-H \ln (p / 1000 \mathrm{hPa})$, where $H=7 \mathrm{~km}$. The EliassenPalm (EP) flux divergence (EPFD) shown in the figures has units of force per unit mass and so represents a tendency term on the right-hand side of the zonal-mean zonal-wind equation (Andrews et al. 1987). To test the hypothesis of critical-layer control of wave drag, it is necessary to perform a wavenumber-frequency analysis of the EPFD. This analysis follows that of Randel and Held (1991). Because disturbances with periods less than 1 day and zonal wavenumbers $k$ from 17 to 32 (the model's truncation wavenumber) have a negligible impact on the stratosphere, the CMAM data were first daily averaged and truncated to a coarser longitudinal grid containing only $k=0-16$. Time series of 120 days, centered in mid-January, were generated from the winds and temperatures for each year and for each simulation to create December-February (DJF) averages. The ends of the time series were tapered before applying the Fourier transform in frequency $\omega$ and $k$ space. Cospectral densities $C(\omega, k)$ were computed from the appropriate quantities, smoothed in frequency using a Gaussian function of $e$-folding width 0.1 day $^{-1}$, and transformed to phase velocity $c$ and $k$ space using 
$C(\omega, k) d \omega=C(c, k) d c$, where $c=\omega a \cos \varphi / k, a$ is the earth's radius, and $\varphi$ is latitude. Although Rossby waves conserve angular phase velocity rather than regular phase velocity during propagation through a zonally homogeneous flow on the sphere, as in Randel and Held (1991) we plot regular phase velocity to allow a direct comparison with the zonal-mean zonal wind. A phase-velocity grid of resolution $\Delta c=1 \mathrm{~m} \mathrm{~s}^{-1}$ was used. Cospectra for each year were averaged over the appropriate time periods and over the three simulations. The plotted cospectral densities in $(c, k)$ space have been divided by $\Delta c$ and therefore have units of the physical quantities. We have checked that the integrated EPFD across all phase speeds closely matches the transient EPFD computed directly from the physical fields.

Note that the wavenumber-frequency analysis requires daily 3D data, which are not available on the CCMVal archive. Thus, it is not possible to extend this analysis to other models using the existing archive.

\section{Analysis}

We start by showing the predicted changes in temperature and zonal wind arising from climate change in the CMAM. Although this is not a new scientific result, it sets the context for the subsequent analysis. Figure 1 shows the differences between the past (1960-79) and future (2080-99) of the annual- and zonal-mean temperature and zonal wind from the ensemble mean of the three simulations, along with the westerly jets for the past. The strengthening of the upper flank of the subtropical jets in both hemispheres is readily apparent. Note that this cannot possibly be the response to a strengthened BDC, because a strengthened BDC would cool the tropics and warm the extratropics and thus act to weaken rather than to strengthen the upper flank of the jets. At middle and high latitudes, the zonal-wind changes differ substantially between the two hemispheres and their interpretation is less straightforward because the zonal winds respond in a first-order way to the dynamical changes (MS09). Our focus here however is on the subtropical changes, because it is the wave drag at subtropical latitudes that is determinative of the net tropical upwelling and thus of the BDC as usually understood (Butchart et al. 2006; MS09).

Because the wavenumber-frequency analysis can only be performed for waves with a nonzero phase velocity, stationary waves are necessarily excluded. It is therefore important to determine how much of the resolved wave drag is missed by this procedure. Although it is often tacitly assumed that planetary waves, especially in the $\mathrm{NH}$, are primarily stationary, the contribution of stationary waves to the driving of the BDC has not been

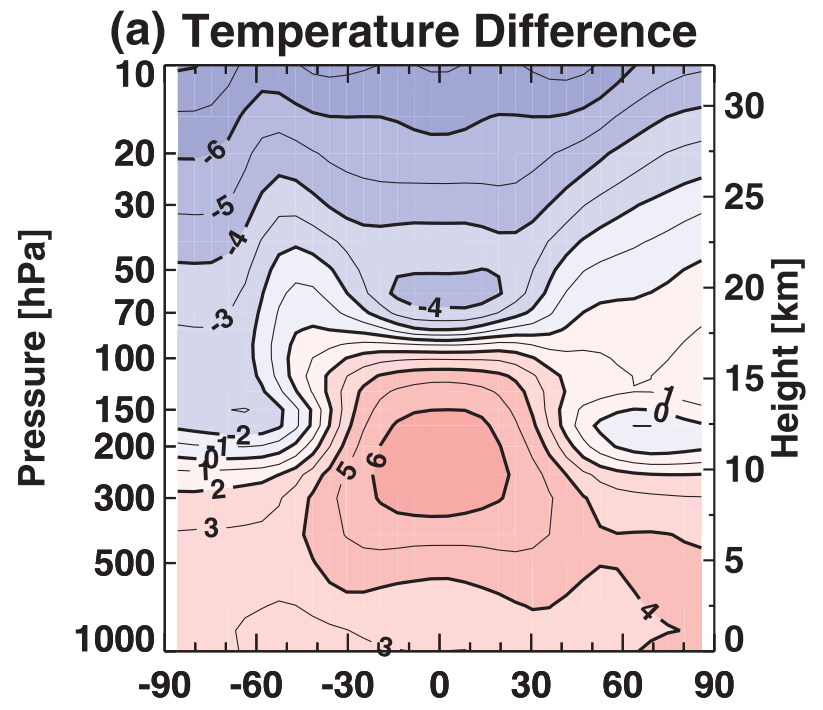

(b) Zonal Wind Difference

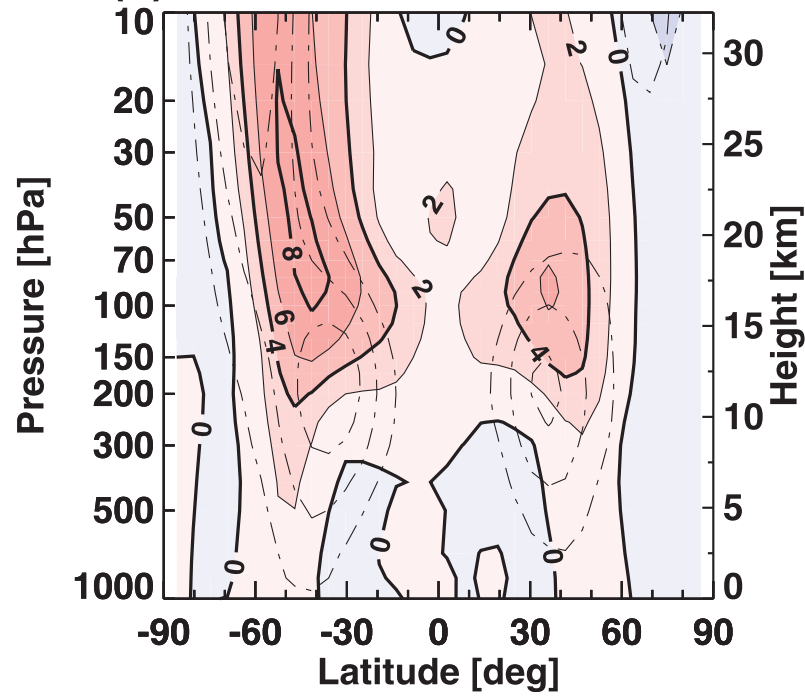

FIG. 1. Difference between the past (1960-79) and the future (2080-99) of the annual- and zonal-mean (a) temperature (K) and (b) zonal wind $\left(\mathrm{m} \mathrm{s}^{-1}\right)$, from the ensemble mean of the three CMAM simulations. The thin dashed-dotted lines in (b) denote the subtropical westerly jet for the past using a contour interval of $10 \mathrm{~m} \mathrm{~s}^{-1}$; for clarity, the zero line and easterlies are not plotted. The subtropical jet maximum is located near $40^{\circ} \mathrm{N}$ and $40^{\circ} \mathrm{S}$.

quantitatively assessed. Figure 2 shows the mass streamfunction for $\mathrm{DJF}$ at $70 \mathrm{hPa}$ inferred from downward control for the past (left) and the difference between the future and past (right). This is a revised version of Fig. 18 of MS09, but with the resolved wave drag now separated into its stationary (monthly mean) and transient (deviations from monthly mean) components. Because the net downward mass flux in each hemisphere is proportional to the mass streamfunction evaluated at the 
(a) Streamfunction DJF (Past)

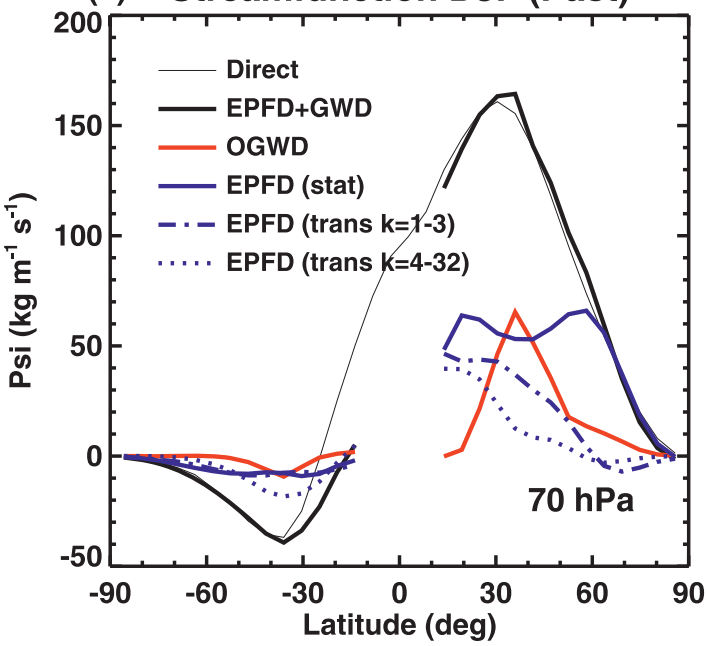

(b) Difference (Future-Past)

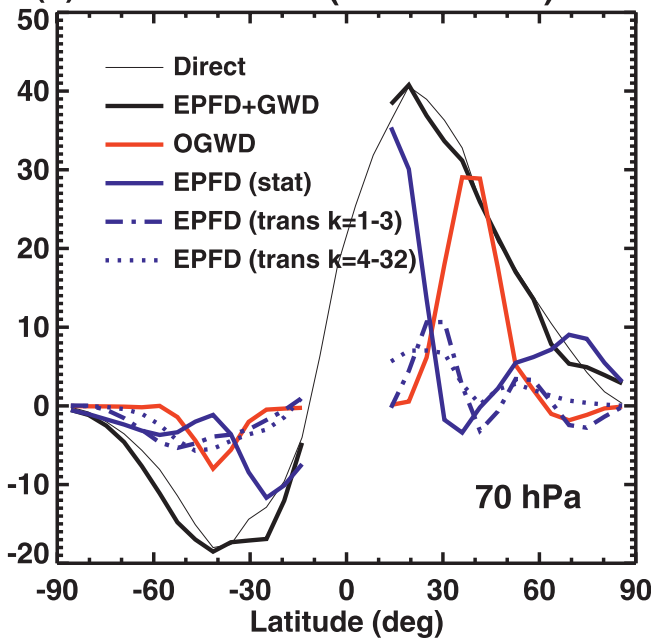

FIG. 2. Downward control mass streamfunction for DJF at $70 \mathrm{hPa}$ for (a) past and (b) future minus past: combined resolved and parameterized wave drag (thick black line); resolved stationary wave drag (solid blue line); transient planetary-scale wave $(k=1-3)$ drag (dashed-dotted line); transient synoptic-scale wave $(k=4-32)$ drag (dotted line); and parameterized orographic GWD (red line). The thin black line denotes the streamfunction computed directly from the vertical residual velocity. The downward control streamfunctions cannot be computed in the tropics.

turnaround latitudes (the extrema of the total streamfunction in Fig. 2a), the future changes in the $\mathrm{NH}$ downward mass flux (which dominates the BDC in DJF) are given by the streamfunction differences evaluated at about $30^{\circ} \mathrm{N}$ (Fig. 2b). The drag from (parameterized) orographic gravity waves, transient planetary-scale waves, and transient synoptic-scale waves all provide roughly equal contributions to the strengthened $\mathrm{NH}$ downwelling, with stationary wave drag providing the smallest contribution.

Table 1 of this paper expands on Table 1 of MS09 by indicating the separate contributions of stationary and transient waves (from both hemispheres) to the increase in net tropical upwelling at $70 \mathrm{hPa}$. It is seen that stationary waves provide only $20 \%$ of the contribution from resolved waves to the annual-mean BDC changes in these simulations, and only $16 \%$ of the DJF changes, which is when the largest absolute changes occur, not only in CMAM but more generally (Butchart et al. 2006, 2010). Although this small contribution of the stationary waves to the resolved wave forcing of the BDC might seem surprising, it is explained by the fact that the changes in lower-stratospheric wave drag at subtropical latitudes are dominated by transient waves, with the changes in stationary wave drag occurring both within the tropics and at higher latitudes (Fig. 2b). Note in particular that the tropical upwelling changes resulting from equatorially trapped quasi-stationary planetary waves discussed in Deckert and Dameris (2008) and Calvo and Garcia (2009) are evident in the large values

TABLE 1. Linear trends in net upward mass flux at $70 \mathrm{hPa}$ calculated using the downward control streamfunction (see MS09 for details) for the sum of resolved and parameterized wave drag (column 2), for transient resolved wave drag (columns 3-5), and for stationary resolved wave drag (columns 6-8). In the latter two cases, the contributions are shown for all $k$ as well as for the separate contributions of planetary waves $(k=1-3)$ and the remainder $(k=4-32$, mainly consisting of synoptic waves). The seasons are DJF, March-May (MAM), JJA, and September-November (SON). The annual mean is given in the bottom row. Quantities in parentheses are the 1- $\sigma$ uncertainties. Trends are computed from 1960 to 2099 using least squares. Negative values indicate a decrease in upwelling. Units are $\mathrm{kt} \mathrm{s}^{-1} \mathrm{yr}^{-1}$.

\begin{tabular}{|c|c|c|c|c|c|c|c|}
\hline \multirow[b]{2}{*}{ Season } & \multirow[b]{2}{*}{ Tot } & \multicolumn{3}{|c|}{ Transient wave drag } & \multicolumn{3}{|c|}{ Stationary wave drag } \\
\hline & & $k=1-32$ & $k=1-3$ & $k=4-32$ & $k=1-32$ & $k=1-3$ & $k=4-32$ \\
\hline DJF & $17.0(0.6)$ & $10.4(0.6)$ & $5.3(0.5)$ & $5.1(0.4)$ & $2.0(0.7)$ & $1.4(0.7)$ & $0.5(0.2)$ \\
\hline MAM & $13.3(0.3)$ & $4.5(0.4)$ & $1.6(0.3)$ & $2.9(0.3)$ & $2.0(0.4)$ & $1.9(0.4)$ & $0.1(0.2)$ \\
\hline JJA & $7.9(0.4)$ & $5.5(0.6)$ & $3.5(0.5)$ & $1.9(0.2)$ & $1.8(0.6)$ & $2.0(0.6)$ & $-0.1(0.1)$ \\
\hline SON & $7.4(0.6)$ & $2.8(0.6)$ & $1.9(0.5)$ & $1.0(0.3)$ & $-0.1(0.5)$ & $0.1(0.5)$ & $-0.1(0.1)$ \\
\hline Annual & $11.5(0.2)$ & $5.8(0.3)$ & $3.1(0.2)$ & $2.7(0.1)$ & $1.4(0.3)$ & $1.3(0.3)$ & $0.1(0.1)$ \\
\hline
\end{tabular}


(a) DJF Past (1960-1979)

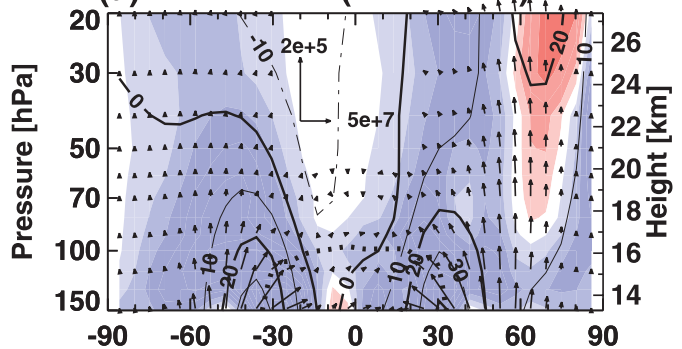

(b) DJF Future (2080-2099)
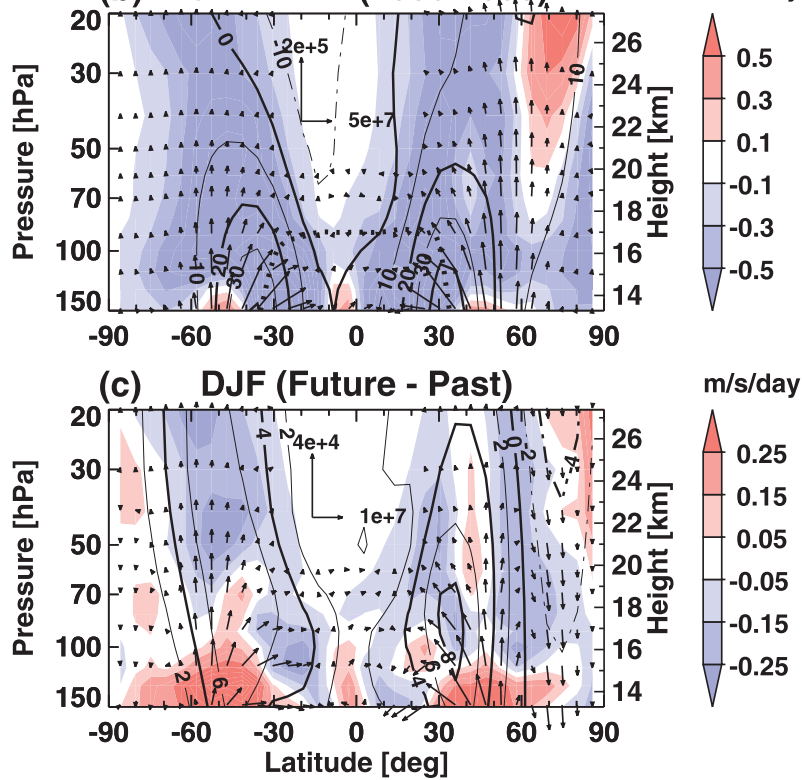

FIG. 3. Zonal-mean zonal wind (contours; $\mathrm{m} \mathrm{s}^{-1}$ ), EPFD (color shading; $\mathrm{m} \mathrm{s}^{-1}$ day $^{-1}$ ), and EP flux vectors from transient waves for DJF averages of the three CMAM simulations for (a) the past, (b) the future, and (c) the difference between the future and the past. The magnitude of the EP flux vector components is given by the perpendicular set of arrows centered near $15^{\circ} \mathrm{S}$ and $40 \mathrm{hPa}$.

of the stationary wave-drag downward control streamfunction differences equatorward of $30^{\circ} \mathrm{N}$ (solid blue line in Fig. 2b). However, they are relatively small at the turnaround latitude and therefore contribute little to the net downward mass flux in the $\mathrm{NH}$.

Figure 3 shows the distribution of the zonal-mean zonal wind together with the EP flux vectors and EPFD associated with transient waves for the past, the future, and the difference between past and future. Because the zonal-wind distributions vary with season, an annual average would smear out the relation between wave drag and critical layers. We therefore focus on DJF, which as noted above is when the largest changes in the BDC are predicted to occur. We are most interested in the changes around $30^{\circ}$ latitude, which is approximately the outer edge of the region of tropical upwelling and hence controls the BDC (Butchart et al. 2006; MS09; Butchart et al. 2010). The (past and future) EPFD is generally negative, implying poleward flow within each hemisphere, so negative changes represent strengthened wave drag and a strengthened circulation. Figure $3 \mathrm{c}$ shows an increased penetration of EP flux into, and a consequent strengthening of the transient EPFD within, the subtropical lower stratosphere in conjunction with the strengthening of the upper flanks of the subtropical jets.

We now test the hypothesis of critical-layer control of the transient wave-drag changes. Figures $4 a-c$ show a latitudinal cross section of Fig. 3 at $50 \mathrm{hPa}$, plotted as a function of zonal phase velocity for EPFD from planetary-scale waves (zonal wavenumbers 1-3). For both past and future, the distribution of EPFD is located along or on the negative side of the zonal-wind profile, as in observations (Randel and Held 1991), which is indicative of the existence of critical layers. That the (negative) EPFD maxima occur for phase velocities on the negative side of the zonal-wind profile is understood to be a finite-amplitude effect (Feldstein and Held 1989). The increase in zonal wind at $50 \mathrm{hPa}$ between past and future, shown in Fig. 4c, therefore leads to strengthened EPFD by allowing disturbances possessing a greater range of phase velocities to reach this altitude. This is true in both hemispheres, but the NH changes are more important for the BDC because they occur in the subtropics.

Figures $4 \mathrm{~d}-\mathrm{f}$ show the same diagnostic, but for zonal wavenumbers 4-16, which include synoptic-scale waves. Here, the shaping of the EPFD distribution by the zonal wind is even more apparent than for the planetary-scale waves, probably reflecting the narrower widths of the breaking regions (because of the shorter zonal wavelengths). As with the planetary-scale waves, critical-layer control is evident in both hemispheres, but the $\mathrm{NH}$ changes are more important for the BDC because they occur in the subtropics. Overall, the character of the EPFD changes and their association with the strengthened zonal wind is the same for both planetary-scale and synoptic-scale waves, showing that the critical-layer mechanism is robust.

Figure 5 is analogous to Fig. 4 but represents a vertical rather than a latitudinal cross section of Fig. 3, taken through the NH subtropics, which is where the most important EPFD changes in DJF are found. The EPFD phase-velocity spectrum for both planetary-scale waves (Figs. 5a,b) and synoptic-scale waves (Figs. 5d,e) is seen to exhibit critical-layer control within the upper flank of the subtropical jet (i.e., within the region of negative vertical zonal-wind shear) for both past and future. As a result, the strengthening of the zonal winds in this region from climate change leads to strengthened EPFD in the lower stratosphere (around $20 \mathrm{~km}$ altitude) in the portion of the 


\section{Planetary-scale waves (DJF $50 \mathrm{hPa}$ )}

(a) Past (1960-1979)

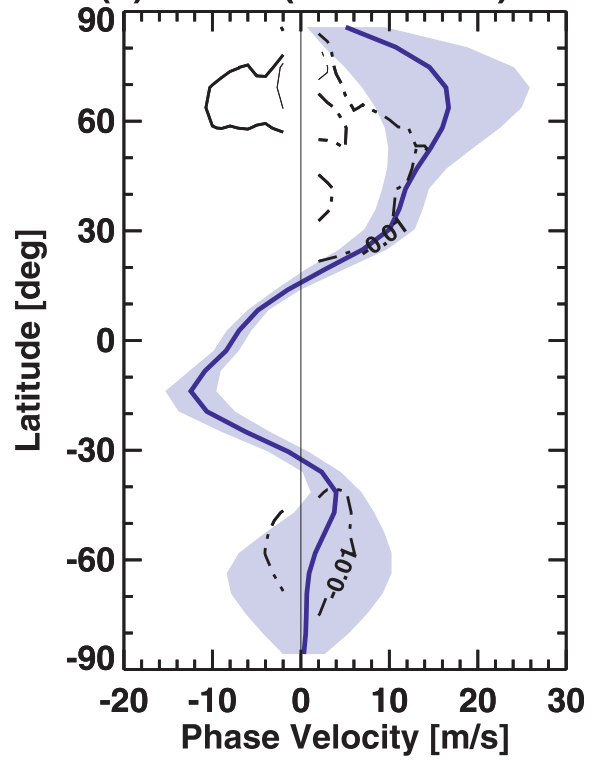

(b) Future (2080-2099)

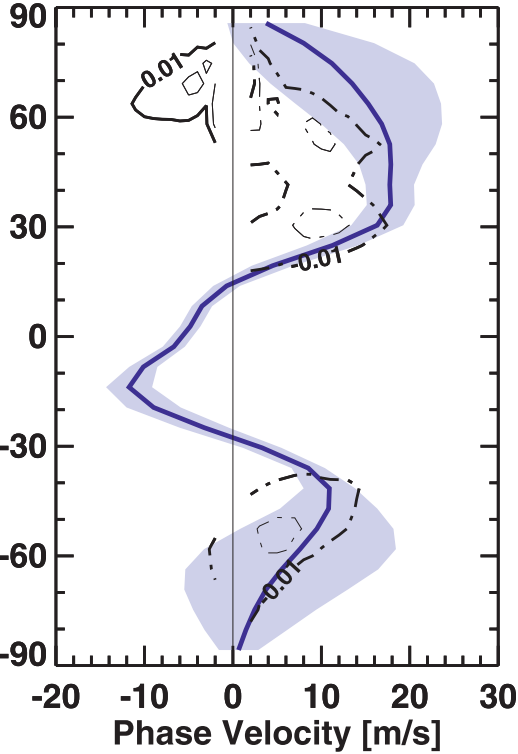

(c) Future - Past

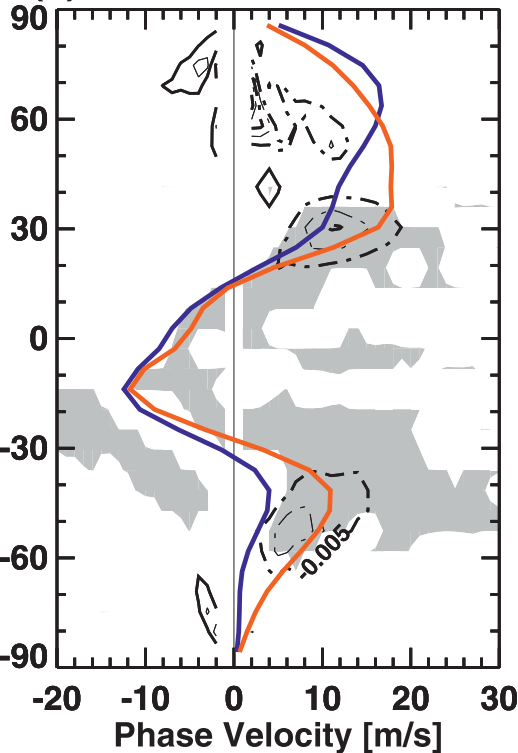

\section{Synoptic-scale waves (DJF $50 \mathrm{hPa}$ )}

(d) Past (1960-1979)

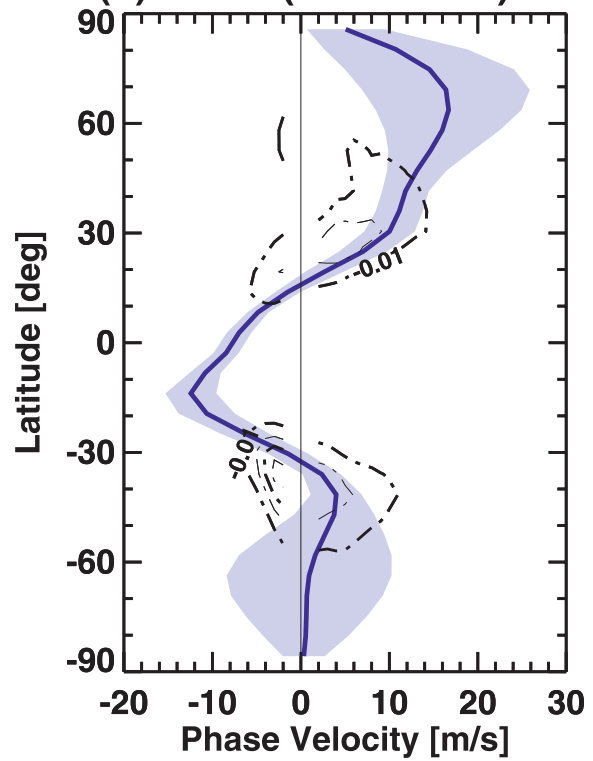

(e) Future (2080-2099)

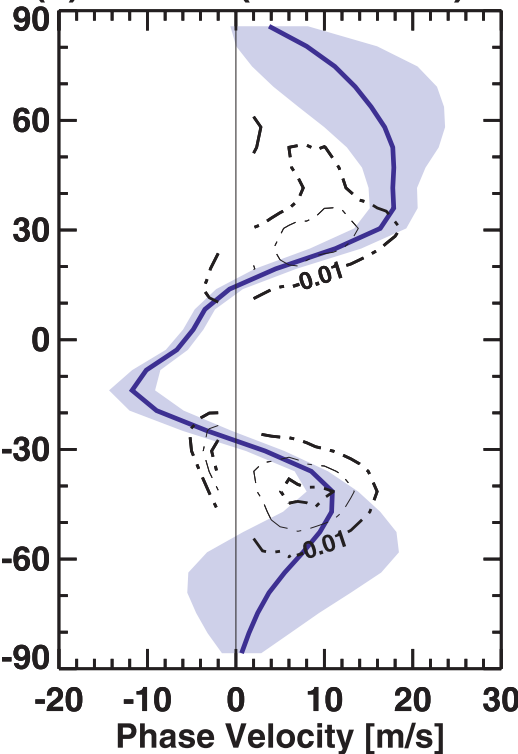

(f) Future - Past

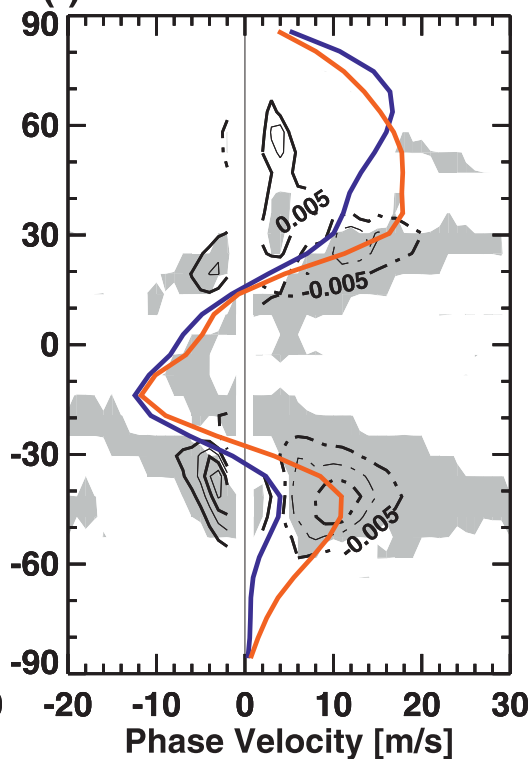

FIG. 4. (a)-(c) EPFD cospectra vs latitude from transient waves for zonal wavenumbers 1-3 at $50 \mathrm{hPa}$ for DJF averages for (a) the past, (b) the future, and (c) the difference between the future and the past. Here, the EPFD is multiplied by the cosine of latitude to represent the torque exerted on the zonal flow. The contour interval is $0.01 \mathrm{~m} \mathrm{~s}^{-1} \mathrm{day}^{-1}$ in (a),(b) and $0.005 \mathrm{~m} \mathrm{~s}^{-1}$ day $^{-1}$ in (c), and the zero line is omitted. Superimposed on (a),(b) are the zonal-mean zonal wind (blue line) and \pm 1 standard deviation of the daily zonal-mean zonal wind about the mean (blue shading). Zonal-wind profiles for the past (blue line) and future (red line) are shown in (c), together with regions where the differences in EPFD are statistically significant at the $99.9 \%$ confidence level (gray shading). (d)-(f) As in (a)-(c), but for zonal wavenumbers $4-16$. 
Planetary-scale waves (DJF $30^{\circ} \mathrm{N}$ )

(a) Past (1960-1979)

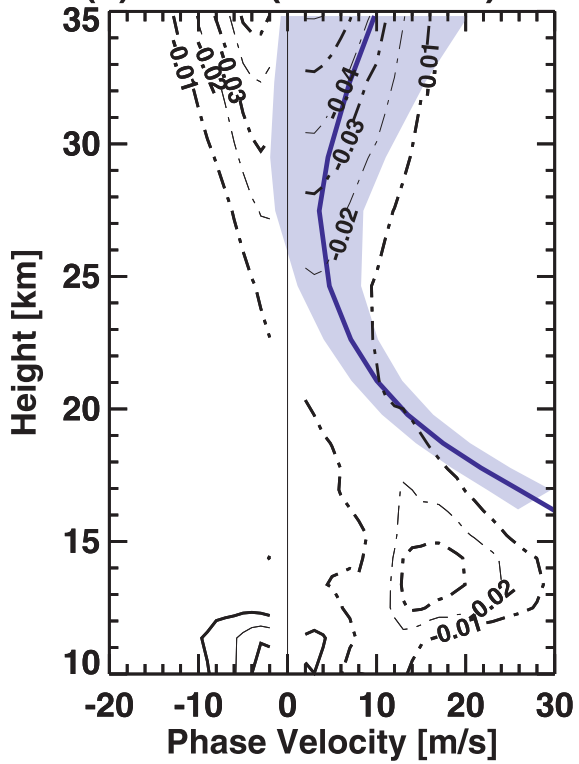

(b) Future (2080-2099)

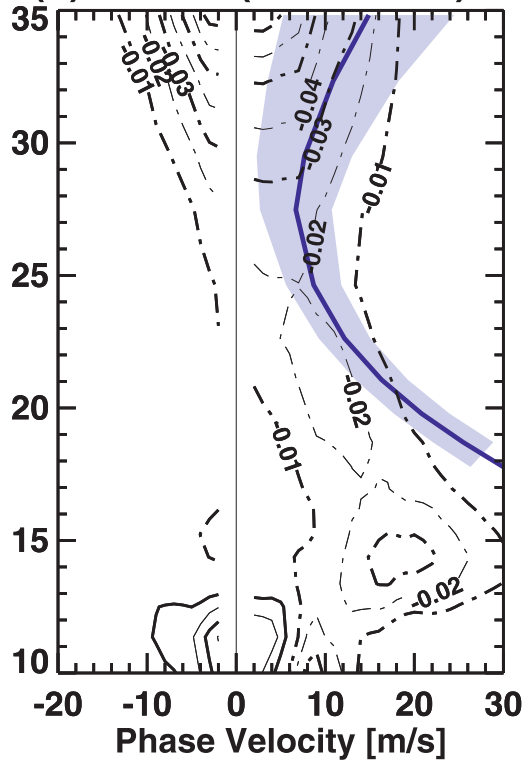

(c) Future - Past

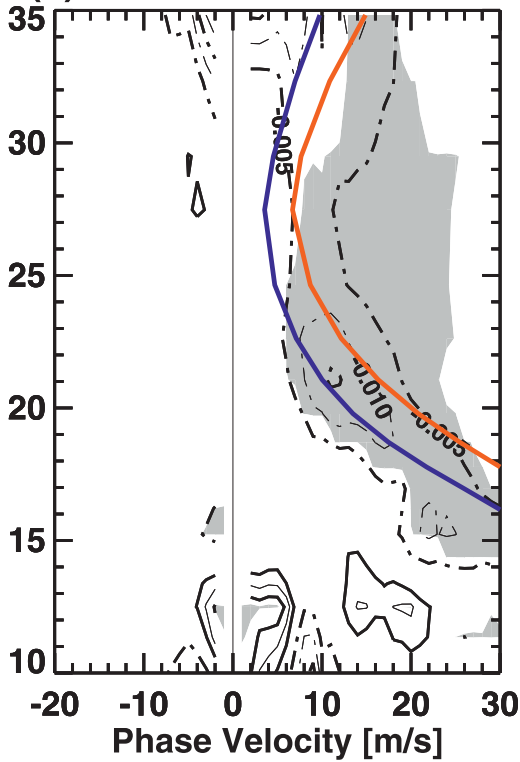

Synoptic-scale waves (DJF $30^{\circ} \mathrm{N}$ )

(d) Past (1960-1979)

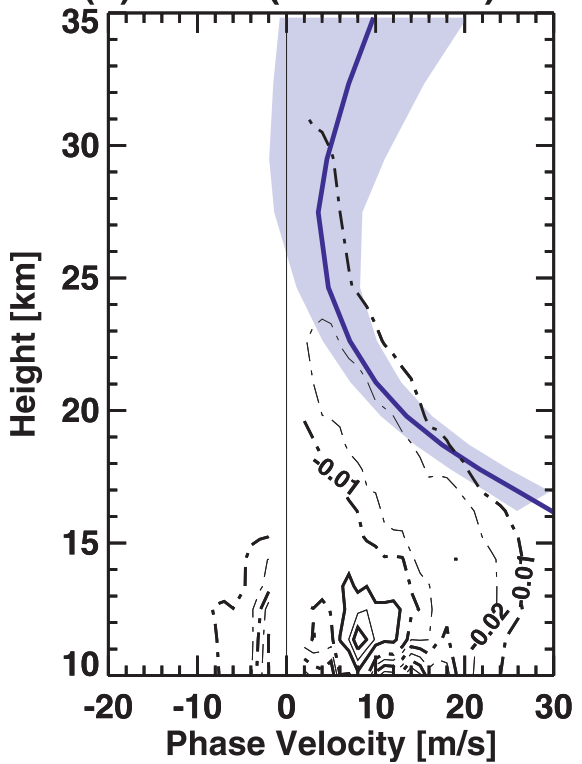

(e) Future (2080-2099)

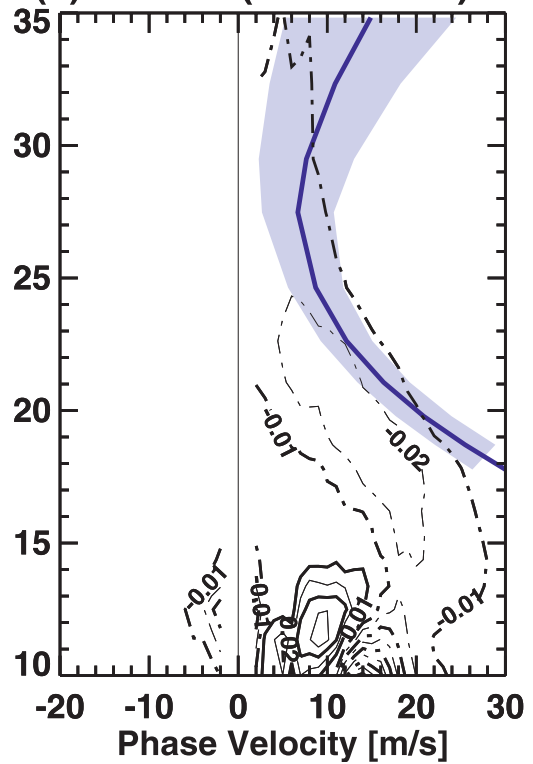

(f) Future - Past

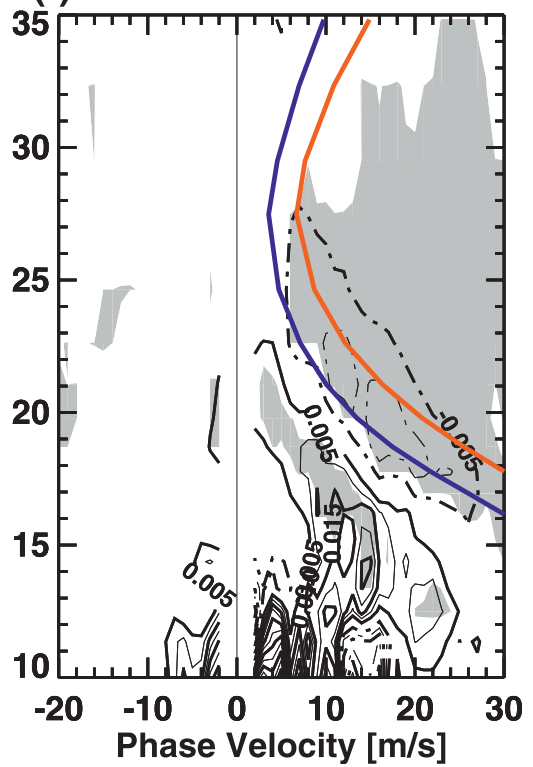

FIG. 5. As in Fig. 4, but for EPFD cospectra vs altitude at $30^{\circ} \mathrm{N}$.

phase-velocity spectrum, between roughly 10 and $20 \mathrm{~m} \mathrm{~s}^{-1}$, that coincides with the strengthened zonal-mean zonal wind in that region (Figs. 5c,f). Figure 5 clearly illustrates how critical-layer control leads to increased vertical penetration of both planetary-scale and synoptic-scale wave drag into the subtropical lower stratosphere. The synoptic-scale EPFD changes (Fig. 5f) take the form of a vertical dipole, which implies a purely vertical shift and accounts for the phase-velocity dipole seen in Fig. 4f. In contrast, the planetary-scale EPFD changes (Fig. 5c) are single signed, which suggests a possible contribution from strengthened tropospheric wave forcing. 


\section{Planetary-scale waves (JJA $50 \mathrm{hPa}$ )}
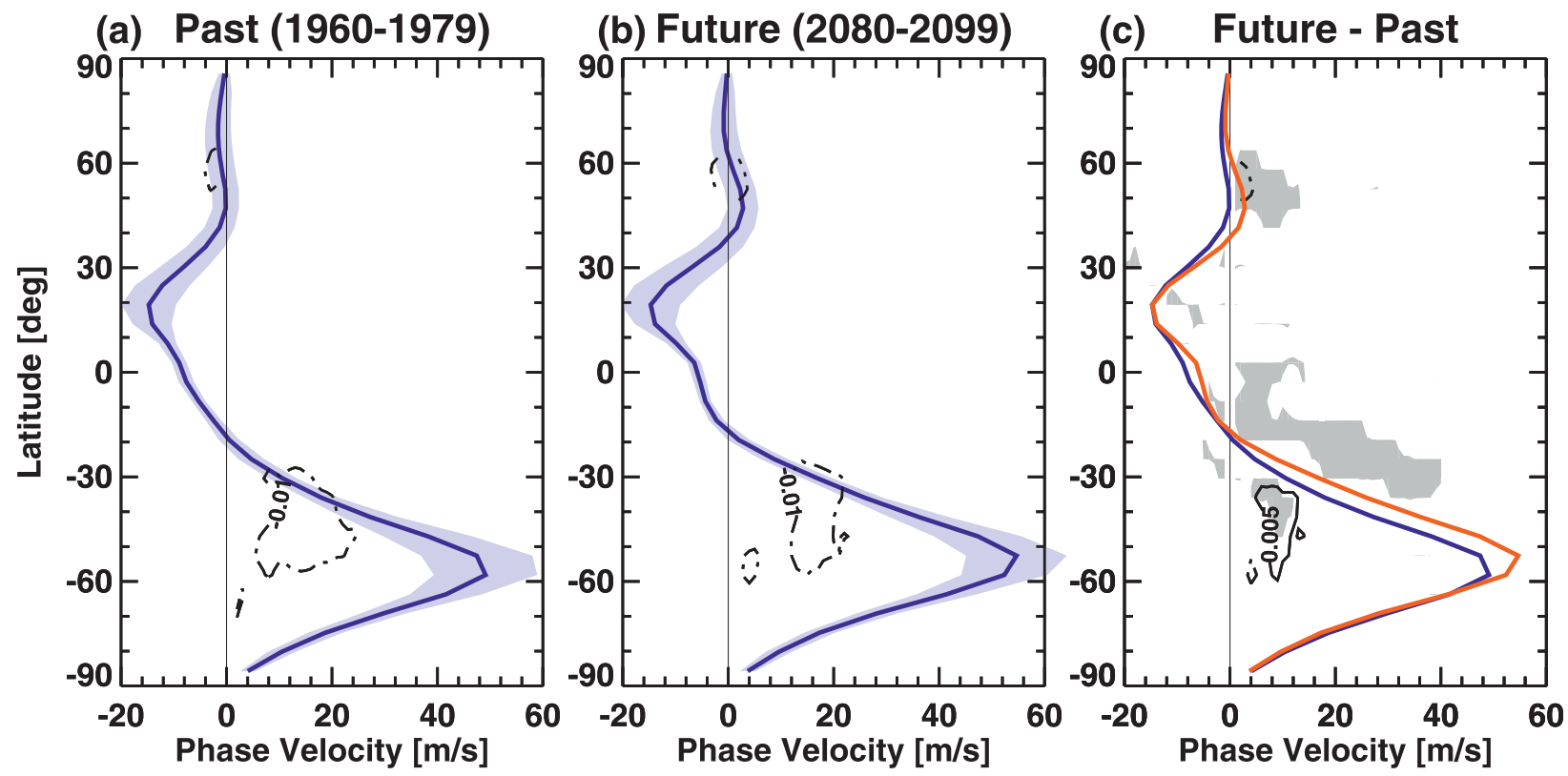

\section{Synoptic-scale waves (JJA $50 \mathrm{hPa}$ )}
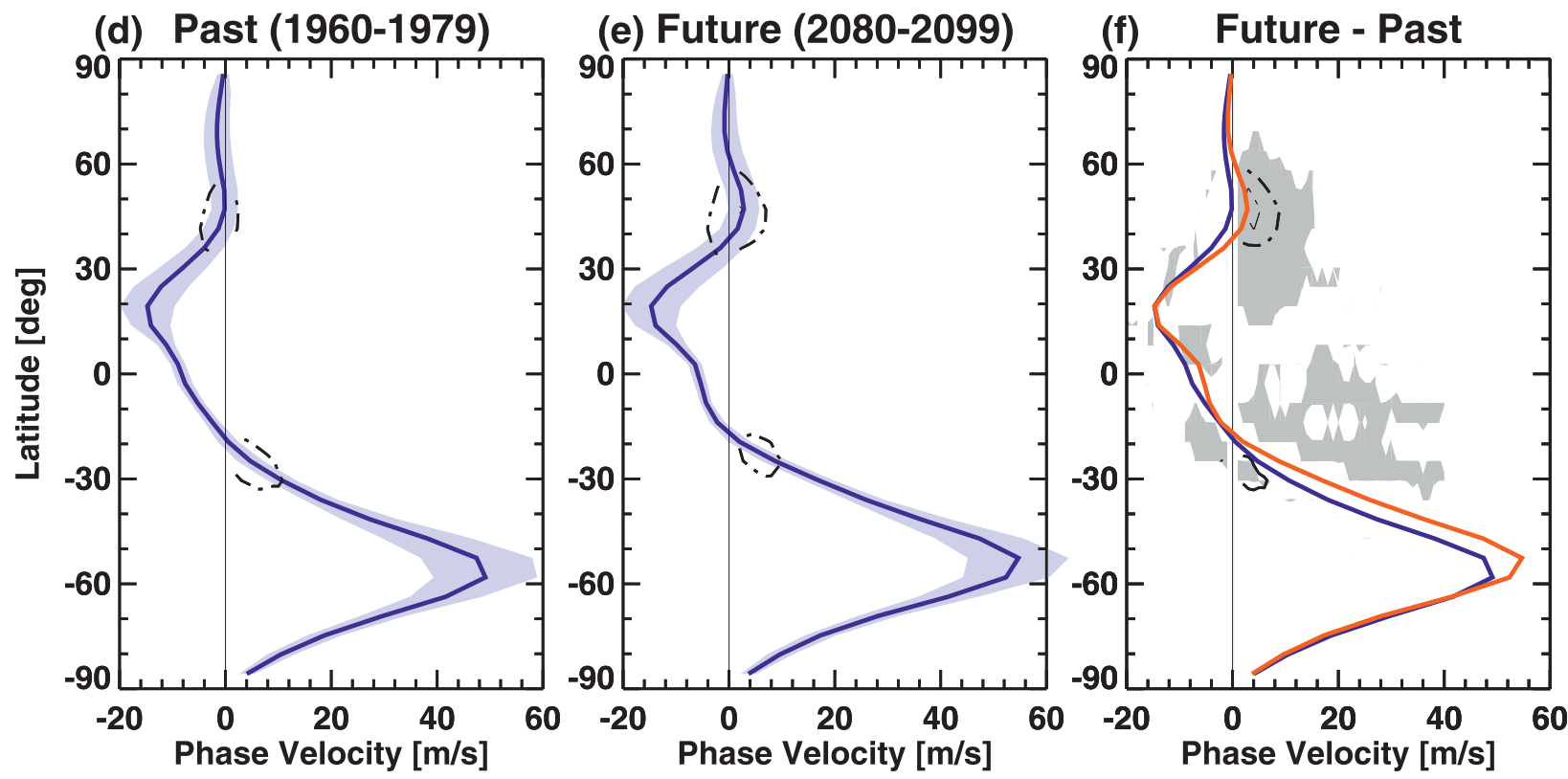

FIG. 6. As in Fig. 4, but for JJA.

Given that the Rossby wave contribution to the strengthening of the BDC in these simulations arises primarily from transient waves, with a significant contribution from synoptic-scale waves, a natural question to ask is whether the mechanism of critical-layer control can also explain the relative weakness of the BDC changes found in June-August (JJA; Table 1). This question is explored in Fig. 6, which is identical to Fig. 4, except that it is for JJA rather than DJF. It is seen that the zonal-wind changes in the subtropical lower stratosphere are much smaller in JJA than in DJF, as is the amount of wave drag that is available to perturb. Nevertheless, critical-layer 
Synoptic-scale waves (DJF $700 \mathrm{hPa}$ )
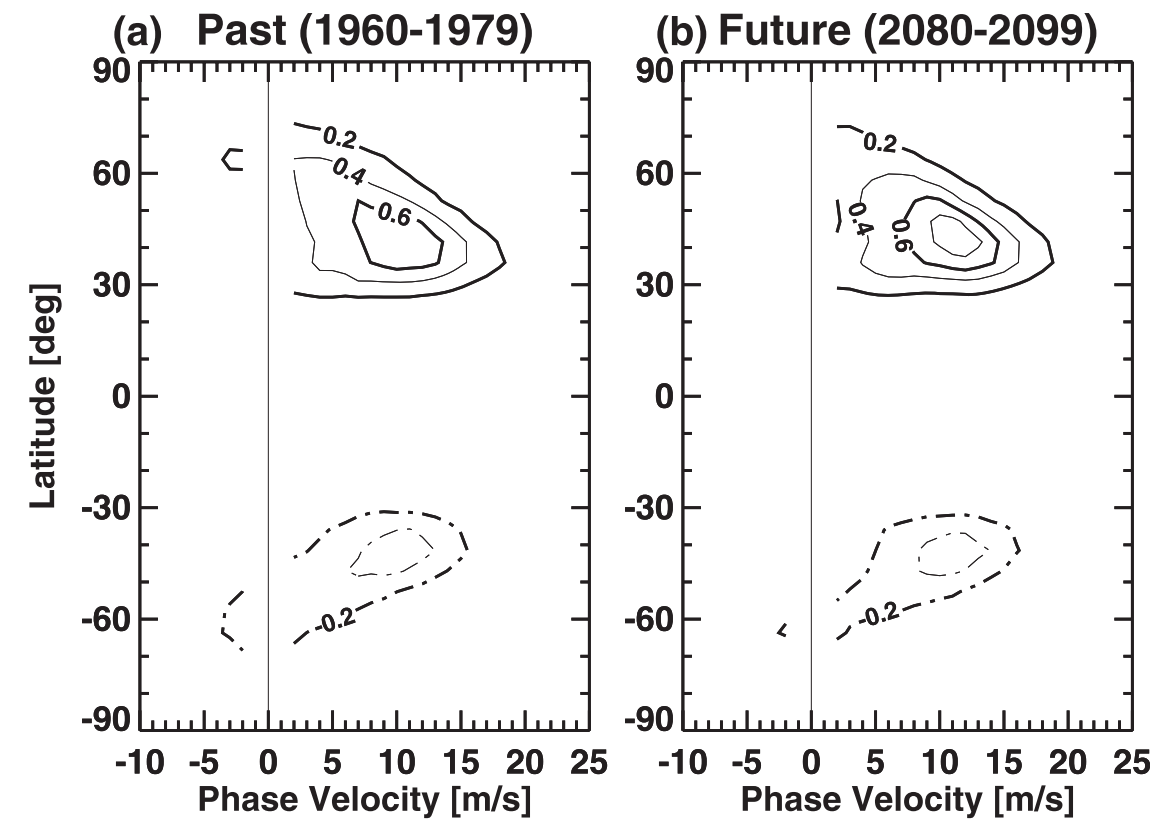

FIG. 7. Meridional heat flux $\left(\mathrm{K} \mathrm{m} \mathrm{s}^{-1}\right)$ for zonal wavenumbers $4-16$ at $700 \mathrm{hPa}$ for DJF averages, for (a) the past and (b) the future. Positive and negative values denote northward and southward heat fluxes, respectively.

control does appear to account for the EPFD changes in the $\mathrm{NH}$, for both synoptic-scale and planetary-scale waves. Note that during JJA the NH turnaround latitudes extend to $40^{\circ} \mathrm{N}$ or higher (Fig. 6a of MS09).

Returning to DJF, Figs. 4 and 5 both show that synopticscale waves are of equal importance as planetary-scale waves to the EPFD changes in the subtropical lower stratosphere, which is the region of most importance for the changes in the BDC. This reflects the quantitative information provided in Table 1. Because the role of synoptic-scale waves in driving the BDC has received little attention and in light of the mechanism proposed by Eichelberger and Hartmann (2005), we consider it further. In particular, we examine whether the changes in synoptic-scale EPFD might be associated with changes in tropospheric wave forcing. Changes in tropospheric moisture and temperature gradients could potentially change both the amplitude and phase velocity of the baroclinic instability that is the main driver of synoptic-scale waves in midlatitudes.

The most direct way to characterize the forcing of synoptic-scale waves by baroclinic instability is by the lower-tropospheric synoptic-scale meridional heat flux (e.g., Randel and Held 1991), which is approximately proportional to the vertical component of the EliassenPalm flux. Figure 7 shows its latitudinal cross section at $700 \mathrm{hPa}$ in DJF for past and future, plotted as a function of zonal phase velocity. No significant change is seen in the Southern Hemisphere (SH), and only a modest change is seen in the NH. To more precisely examine the latter change, Fig. 8a shows the phase-velocity distribution of the $\mathrm{NH}$ meridional heat flux, averaged over $30^{\circ}-60^{\circ} \mathrm{N}$, which encompasses most of the heat flux. Because of meridional propagation, these waves can all potentially reach the subtropical lower stratosphere. Comparison of past and future reveals a modest strengthening and shift of lower-tropospheric heat flux to larger phase speeds. However, Fig. 8b shows that the change in lower-stratospheric synoptic-scale EPFD in subtropical latitudes is mainly explained by a shift of the phasevelocity distribution corresponding to the local change in zonal-mean zonal wind (which is what one would expect from critical-layer control), without any need to consider changes in tropospheric wave forcing. This is seen by the blue dashed curve, which shows the future wave drag shifted to the left by the magnitude of the zonal-mean zonal-wind change $\left(6.3 \mathrm{~m} \mathrm{~s}^{-1}\right)$ at that location. The close agreement between the blue dashed and blue solid curves in Fig. 8b shows that the wave-drag spectrum is mainly responding to the local change in zonal wind through critical-layer dissipation, rather than to the much smaller changes (roughly $1 \mathrm{~m} \mathrm{~s}^{-1}$ ) in phase velocity of the waves at the source region. (Moreover, a strengthened heat flux in the future would imply breaking 
(a) Synoptic-scale heat flux $\left(30^{\circ}-60^{\circ} \mathrm{N} 700 \mathrm{hPa}\right)$

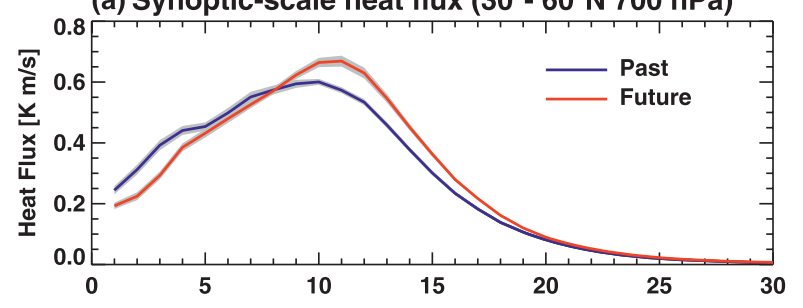

(b) Synoptic-scale wave drag $\left(30^{\circ} \mathrm{N} 50 \mathrm{hPa}\right)$

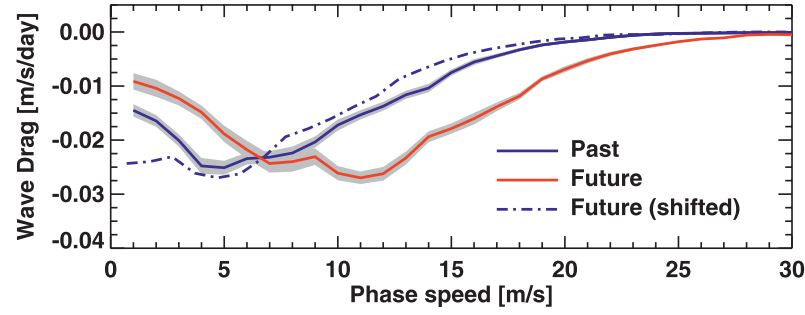

FIG. 8. (a) Meridional heat flux for zonal wavenumbers 4-16 at $700 \mathrm{hPa}$ averaged over $30^{\circ}-60^{\circ} \mathrm{N}$ for DJF for the past (blue line) and the future (red line). Shading denotes \pm 1 standard error of the mean. (b) As in (a), but for EPFD at $50 \mathrm{hPa}$ and $30^{\circ} \mathrm{N}$. The dashed blue line in (b) shows the future values shifted to the left by the mean zonalwind change at the same location, which is $6.3 \mathrm{~m} \mathrm{~s}^{-1}$. Note that the EPFD is negative, so magnitudes increase downward in (b).

at larger intrinsic phase speeds and thus at lower altitudes and more negative phase velocities, the opposite of what is seen here.) Thus, the changes in synoptic-scale EPFD seen in Figs. 4 and 5 can be primarily attributed to changes in lower-stratospheric winds through the proposed mechanism of critical-layer control, rather than to a change in the spectrum of the baroclinic wave forcing.

\section{Conclusions and discussion}

We have shown that, in CMAM simulations, most $(80 \%)$ of the contribution of resolved waves to the strengthened BDC-defined as the net tropical upwelling at $70 \mathrm{hPa}$-in response to (GHG induced) climate change arises from transient waves, with roughly equal contributions from planetary-scale and synoptic-scale waves (Table 1). Although the small contribution from stationary waves to the strengthened BDC might seem surprising, it is explained by the fact that the changes in lower-stratospheric transient wave drag occur mainly at subtropical latitudes, which is where the mass outflow from the tropics occurs, whereas the changes in stationary wave drag occur mainly within the tropics (where they contribute to recirculation within the tropics) or at higher latitudes (where they contribute to polar downwelling) (Fig. 2). Nevertheless, changes in upwelling within the deep tropics, which are predicted to result from an increase in drag from equatorially trapped quasi-stationary Rossby waves arising from strengthened tropical convection in a warmer troposphere (Deckert and Dameris 2008), with a maximum effect in boreal summer, can certainly affect the distribution of temperature and tracers within the deep tropics.

We have furthermore shown that the changes in transient wave drag, of both planetary and synoptic scale, are explainable in terms of a simple and robust dynamical mechanism, namely the observed critical-layer control of Rossby wave breaking (Randel and Held 1991). In particular, the tropospheric warming that is robustly expected from climate change leads to a strengthening of the upper flanks of the subtropical jets, which causes the critical layers on the equatorward side of the jets to move upward, and with them the Rossby wave drag, allowing more Rossby wave activity to penetrate into the subtropical lower stratosphere (Figs. 4, 5). Because the subtropics represent the critical region for wave driving of the Brewer-Dobson circulation, the circulation is thereby strengthened.

The largest absolute changes in the BDC are predicted to occur in DJF, both in CMAM (Table 1) and more generally (Butchart et al. 2006, 2010). Critical-layer control of Rossby wave breaking for both planetary-scale and synoptic-scale waves is apparent in DJF in both hemispheres, but the $\mathrm{NH}$ changes are more important for the BDC because they occur in the subtropics, whereas the $\mathrm{SH}$ changes are located more in the midlatitudes (Fig. 4). This is consistent with the fact that in DJF the strengthened BDC is mainly associated with increased downwelling in the NH (see Table 2 of MS09). In JJA, the zonal-wind changes in the subtropical lower stratosphere are much smaller than in DJF, as is the amount of wave drag that is available to perturb. Nevertheless, critical-layer control of Rossby wave breaking for both synoptic-scale and planetary-scale waves is apparent in the NH during JJA (Fig. 6).

Because the predicted increase in parameterized lowerstratospheric orographic GWD may also be understood as an upward shift of the wave breaking levels due to the strengthened upper flank of the subtropical jet $(\mathrm{Li}$ et al. 2008; MS09; Butchart et al. 2010), our proposed mechanism of critical-layer control of Rossby wave breaking provides a unified perspective on wave-drag contributions to the strengthened BDC. Considered together, these two robust responses to climate change account for nearly all the BDC changes in these simulations. This may explain the robustness of the predicted BDC changes in different models, despite the fact that the relative contributions of resolved and parameterized wave drag to these changes vary substantially between models (Butchart et al. 2010). Much of this sensitivity may arise from quantitative differences in the orographic GWD parameterizations in the different models together with differences in the location 
of the turnaround latitudes between upwelling and downwelling, which can strongly affect the relative contribution of orographic GWD (MS09).

Critical-layer control of Rossby wave breaking has also been invoked as a mechanism to explain the observed zonally symmetric extratropical tropospheric circulation response to El Niño (Robinson 2002; Lu et al. 2008). In that case, it is the latitudinal shift of the Rossby wave critical layers in the subtropical upper troposphere that is important, because this leads to latitudinal shifts in the horizontal momentum fluxes and hence in the surface winds. In the case of GHG-induced climate change, however, Lu et al. (2008) find that the subtropical zonalwind changes in the upper troposphere are too weak for this mechanism to be operative.

The wavenumber-frequency analysis performed here excludes stationary (zero phase velocity) Rossby waves, which are generally of planetary scale and also play a role in driving the BDC (Randel et al. 2008) and its predicted changes, albeit a minor role in the changes discussed here. Stationary Rossby waves may also be expected to be subject to critical-layer control (McIntyre and Palmer 1983), and their behavior may be qualitatively inferred by interpolating the EPFD contours between waves with positive and negative phase velocities in Figs. 4-6.

We have shown that the mechanism of strengthened baroclinic instability, proposed by Eichelberger and Hartmann (2005) on the basis of a highly idealized study, does not appear to be operative in these simulations and that the changes in synoptic-scale EPFD are primarily a result of critical-layer control within the lower stratosphere (Fig. 8). Although planetary-scale EPFD also exhibits critical-layer control, its changes (Figs. 4c, 5c) exhibit less of a dipole character than the synoptic-scale EPFD changes do (Figs. 4f, 5f), suggesting that there may also be changes in the transient planetary-wave forcing emanating from the troposphere. Further studies are needed to elucidate the mechanisms for such changes as well as possible changes in the forcing of stationary waves.

Although the strengthening of the BDC in response to climate change is a robust prediction of the models, the observational evidence for this phenomenon is mixed. Because reanalyses are not considered sufficiently reliable to provide credible estimates of long-term changes in either tropical upwelling (Iwasaki et al. 2009) or subtropical wave drag, attention has focused instead on indirect inferences from more directly measured quantities. A strengthened BDC should lead to a younger age of air and indeed does so in the models (Butchart et al. 2010). Although estimates of age of air changes inferred from in situ measurements at stratospheric midlatitudes do not show any significant trend over the past $30 \mathrm{yr}$, given the considerable uncertainties they are also not able to exclude, at a high level of confidence, the small decrease predicted by most models over that period (Engel et al. 2009; Waugh 2009). Moreover the ability to infer age of air trends from observed tracers such as $\mathrm{SF}_{6}$ and $\mathrm{CO}_{2}$, which vary nonlinearly with time, has recently been questioned (Garcia et al. 2011). A strengthened tropical upwelling would also lead to a decrease in both temperature and ozone in the tropical lower stratosphere. The former appears to be consistent with observed temperature changes from radiosondes during 1979-2003 (Thompson and Solomon 2005), and the latter appears to be consistent with the vertical profile of observed ozone trends from the Stratospheric Aerosol and Gas Experiment (SAGE) over 1979-2005 (Randel and Wu 2007), although it must be noted that the vertically integrated SAGE trends in the tropics are inconsistent with the column ozone trends. Longer time series of precise, vertically resolved measurements of temperature and trace gases are needed to better test the models' prediction of a strengthened BDC in the real atmosphere.

Acknowledgments. This work was funded by the Canadian Foundation for Climate and Atmospheric Sciences through the C-SPARC project. The authors thank Dr. Isla Simpson for helpful comments on the manuscript and two anonymous reviewers for their constructive reviews and valuable suggestions.

\section{REFERENCES}

Andrews, D. G., J. R. Holton, and C. B. Leovy, 1987: Middle Atmosphere Dynamics. Academic Press, 489 pp.

Butchart, N., and A. A. Scaife, 2001: Removal of chlorofluorocarbons by increased mass exchange between the stratosphere and troposphere in a changing climate. Nature, 410, 799-802.

- and Coauthors, 2006: Simulations of anthropogenic change in the strength of the Brewer-Dobson circulation. Climate Dyn., 27, 727-741.

— of twenty-first century stratospheric climate and circulation changes. J. Climate, 23, 5349-5374.

Calvo, N., and R. R. Garcia, 2009: Wave forcing of the tropical upwelling in the lower stratosphere under increasing concentrations of greenhouse gases. J. Atmos. Sci., 66, 3184-3196.

Deckert, R., and M. Dameris, 2008: Higher tropical SSTs strengthen the tropical upwelling via deep convection. Geophys. Res. Lett., 35, L10813, doi:10.1029/2008GL033719.

de Grandpré, J., S. R. Beagley, V. I. Fomichev, E. Griffioen, J. C. McConnell, A. S. Medvedev, and T. G. Shepherd, 2000: Ozone climatology using interactive chemistry: Results from the Canadian Middle Atmosphere Model. J. Geophys. Res., 105, 26 475-26 491.

Eichelberger, S. J., and D. L. Hartmann, 2005: Changes in the strength of the Brewer-Dobson circulation in a simple AGCM. Geophys. Res. Lett., 32, L15807, doi:10.1029/2005GL022924. 
Engel, A., and Coauthors, 2009: Age of stratospheric air unchanged within uncertainties over the past 30 years. Nat. Geosci., 2, 28-31.

Eyring, V., and Coauthors, 2006: Assessment of temperature, trace species, and ozone in chemistry-climate model simulations of the recent past. J. Geophys. Res., 111, D22308, doi:10.1029/ 2006JD007327.

—_, and Coauthors, 2007: Multimodel projections of stratospheric ozone in the 21st century. J. Geophys. Res., 112, D16303, doi:10.1029/2006JD008332.

Feldstein, S. B., and I. M. Held, 1989: Barotropic decay of baroclinic waves in a two-layer beta-plane model. J. Atmos. Sci., 46, 3416-3430.

Fomichev, V. I., A. I. Jonsson, J. de Grandpré, S. R. Beagley, C. McLandress, K. Semeniuk, and T. G. Shepherd, 2007: Response of the middle atmosphere to $\mathrm{CO}_{2}$ doubling: Results from the Canadian Middle Atmosphere Model. J. Climate, 20, 1121-1144.

Garcia, R. R., and W. J. Randel, 2008: Acceleration of the BrewerDobson circulation due to increases in greenhouse gases. J. Atmos. Sci., 65, 2731-2739.

,-- , and D. E. Kinnison, 2011: On the determination of age of air trends from atmospheric trace species. J. Atmos. Sci., 68 , 139-154.

Haynes, P. H., 2003: Critical layers. Encyclopedia of Atmospheric Sciences, J. R. Holton, J. A. Curry, and J. A. Pyle, Eds., Academic Press, 582-589.

— C. J. Marks, M. E. McIntyre, T. G. Shepherd, and K. P. Shine, 1991: On the "downward control" of extratropical diabatic circulations by eddy-induced mean zonal forces. J. Atmos. Sci., 48, 651-678.

Hegglin, M. I., and T. G. Shepherd, 2007: $\mathrm{O}_{3}-\mathrm{N}_{2} \mathrm{O}$ correlations from the Atmospheric Chemistry Experiment: Revisiting a diagnostic of transport and chemistry in the stratosphere. J. Geophys. Res., 112, D19301, doi:10.1029/2006JD008281.

_ index and stratosphere-to-troposphere ozone flux. Nat. Geosci., 2, 687-691.

Holton, J. R., 1990: On the global exchange of mass between the stratosphere and troposphere. J. Atmos. Sci., 47, 392-395.

— , P. H. Haynes, M. E. McIntyre, A. R. Douglass, R. B. Rood, and L. Pfister, 1995: Stratosphere-troposphere exchange. Rev. Geophys., 33, 403-439.

Iwasaki, T., H. Hamada, and K. Miyazaki, 2009: Comparisons of Brewer-Dobson circulations diagnosed from reanalyses. J. Meteor. Soc. Japan, 87, 997-1006.

Li, F., J. Austin, and R. J. Wilson, 2008: The strength of the Brewer-Dobson circulation in a changing climate: Coupled chemistry-climate model simulations. J. Climate, 21, 40-57.

Lu, J., G. Chen, and D. M. W. Frierson, 2008: Response of the zonal mean atmospheric circulation to El Niño versus global warming. J. Climate, 21, 5835-5851.

Mahfouf, J. F., D. Cariolle, J.-F. Royer, J.-F. Geleyn, and B. Timbal, 1994: Response of the Météo-France climate model to changes in $\mathrm{CO}_{2}$ and sea surface temperature. Climate Dyn., 9, 345-362.

McIntyre, M. E., and T. N. Palmer, 1983: Breaking planetary waves in the stratosphere. Nature, 305, 593-600.

McLandress, C., and T. G. Shepherd, 2009: Simulated anthropogenic changes in the Brewer-Dobson circulation, including its extension to high latitudes. J. Climate, 22, 1516-1540.
Olsen, M. A., M. R. Schoeberl, and J. E. Nielsen, 2007: Response of stratospheric circulation and stratosphere-troposphere exchange to changing sea surface temperatures. J. Geophys. Res., 112, D16104, doi:10.1029/2006JD008012.

Oman, L., D. W. Waugh, S. Pawson, R. S. Stolarski, and P. A. Newman, 2009: On the influence of anthropogenic forcings on changes in the stratospheric mean age. J. Geophys. Res., 114, D03105, doi:10.1029/2008JD010378.

Plumb, R. A., 2002: Stratospheric transport. J. Meteor. Soc. Japan, 80, 793-809.

, and J. Eluszkiewicz, 1999: The Brewer-Dobson circulation: Dynamics of the tropical upwelling. J. Atmos. Sci., 56, 868-890.

Randall, D. A., and Coauthors, 2007: Climate models and their evaluation. Climate Change 2007: The Physical Science Basis, S. Solomon et al., Eds., Cambridge University Press, 589-662.

Randel, W. J., and I. M. Held, 1991: Phase speed spectra of transient eddy fluxes and critical layer absorption. J. Atmos. Sci., 48, 688-697.

, and F. Wu, 2007: A stratospheric ozone profile data set for 1979-2005: Variability, trends, and comparisons with column ozone data. J. Geophys. Res., 112, D06313, doi:10.1029/ 2006JD007339.

— R. Garcia, and F. Wu, 2008: Dynamical balances and tropical stratospheric upwelling. J. Atmos. Sci., 65, 3584-3595.

Rind, D., R. Suozzo, N. K. Balachandran, and M. J. Prather, 1990: Climate change and the middle atmosphere. Part I: The doubled $\mathrm{CO}_{2}$ climate. J. Atmos. Sci., 47, 475-494.

—, D. Shindell, P. Lonergan, and N. K. Balachandran, 1998: Climate change and the middle atmosphere. Part III: The doubled $\mathrm{CO}_{2}$ climate revisited. J. Climate, 11, 876-894.

—, P. Lonergan, N. K. Balachandran, and D. Shindell, 2002: $2 \mathrm{xCO}_{2}$ and solar variability influences on the troposphere through wave-mean interaction. J. Meteor. Soc. Japan, 80, 863-876.

Robinson, W. A., 2002: On the midlatitude thermal response to tropical warmth. Geophys. Res. Lett., 29, 1190, doi:10.1029/ 2001 GL014158.

Scinocca, J. F., and P. H. Haynes, 1998: Dynamical forcing of stratospheric planetary waves by tropospheric baroclinic eddies. J. Atmos. Sci., 55, 2361-2392.

—, N. A. McFarlane, M. Lazare, J. Li, and D. Plummer, 2008: The CCCma third generation AGCM and its extension into the middle atmosphere. Atmos. Chem. Phys., 8, 7055-7074.

Semeniuk, K., and T. G. Shepherd, 2001: Mechanisms for tropical upwelling in the stratosphere. J. Atmos. Sci., 58, 3097-3115.

Shepherd, T. G., 2000: The middle atmosphere. J. Atmos. Sol. Terr. Phys., 62, 1587-1601.

, 2007: Transport in the middle atmosphere. J. Meteor. Soc. Japan, 85B, 165-191.

_- 2008: Dynamics, stratospheric ozone, and climate change. Atmos.-Ocean, 46, 117-138.

Sigmond, M., P. C. Siegmund, E. Manzini, and H. Kelder, 2004: A simulation of the separate climate effects of middle atmospheric and tropospheric $\mathrm{CO}_{2}$ doubling. J. Climate, 17, 2352-2367.

Thompson, D. W. J., and S. Solomon, 2005: Recent stratospheric climate trends as evidenced in radiosonde data: Global structure and tropospheric linkages. J. Climate, 18, 4785-4795.

Waugh, D. W., 2009: The age of stratospheric air. Nat. Geosci., 2 , 14-16.

-, and V. Eyring, 2008: Quantitative performance metrics for stratospheric-resolving chemistry-climate models. Atmos. Chem. Phys., 8, 5699-5713. 